\title{
Michele Mastroianni, La «Bradamante» di Robert Garnier. Una rilettura dell'Ariosto tra Controriforma e Barocco
}

\section{Filippo Fassina}

\section{(2) OpenEdition \\ 1 Journals}

\section{Edizione digitale}

URL: http://journals.openedition.org/studifrancesi/1119

DOI: 10.4000/studifrancesi. 1119

ISSN: 2421-5856

\section{Editore}

Rosenberg \& Sellier

\section{Edizione cartacea}

Data di pubblicazione: 1 novembre 2014

Paginazione: 583

ISSN: 0039-2944

\section{Notizia bibliografica digitale}

Filippo Fassina, « Michele Mastroianni, La «Bradamante» di Robert Garnier. Una rilettura dell'Ariosto tra Controriforma e Barocco », Studi Francesi [Online], 174 (LVIII | III) | 2014, online dal 01 novembre 2014 consultato il 18 septembre 2020. URL : http://journals.openedition.org/studifrancesi/1119; DOI : https://doi.org/10.4000/studifrancesi. 1119

Questo documento è stato generato automaticamente il 18 settembre 2020.

\section{cc) (†) $\odot$}

Studi Francesi è distribuita con Licenza Creative Commons Attribuzione - Non commerciale - Non opere derivate 4.0 Internazionale. 


\title{
Michele Mastroianni, La «Bradamante» di Robert Garnier. Una rilettura dell'Ariosto tra Controriforma e Barocco
}

\author{
Filippo Fassina
}

\section{NOTIZIA}

MICHELE MASTROIANNI, La «Bradamante» di Robert Garnier. Una rilettura dell'Ariosto tra Controriforma e Barocco, «Annali dell'Istituto Orientale di Napoli», Sezione Romanza, LIII, 1-2, 2011, pp. 39-77; ID., Una trasposizione francese dell'Ariosto alla luce di un dibattito posttridentino, in AA. VV., Da un genere all'altro. Trasposizioni e riscritture nella letteratura francese, Roma, Aracne, 2012, pp. 101-110.

1 Nel primo denso saggio sulla Bradamante di Garnier, l'A. analizza la pièce di argomento ariostesco nella prospettiva dell'intertestualità e di quei meccanismi di passaggio di genere che governano le riscritture cinque-secentesche, sia dei grandi testi classici greco-latini sia di quegli autori della contemporaneità (soprattutto italiani e spagnoli) che godono diffusione in Francia attraverso edizioni, traduzioni, imitazioni. L'episodio delle combattute nozze di Bradamante - uno di quelli conclusivi dell'orlando furioso - ha goduto per tre secoli di molteplici riscritture in Francia (Cioranescu ne ha repertoriate venti fra il 1571 e il 1851): lo stesso Mastroianni conclude il suo studio con un riferimento alle due Bradamantes secentesche, quella di La Calprenède (1637) e quella di Thomas Corneille (1692), che testimoniano la fortuna di un tema considerato banco di prova per l'esercizio di rielaborazione. L'indagine dell'A. intende dimostrare come per l'intermediario del testo ariostesco confluiscano nella pièce di Garnier modelli di genere diverso e come, pertanto, «questa pièce sia, in un gioco di riferimenti intertestuali, un continuo esercizio di variazione linguistica, nella misura in cui la commistione di 
generi diventa anche e soprattutto commistione di linguaggi». In primo luogo, infatti, l'analisi di Mastroianni individua i diversi livelli linguistici, nel sovrapporsi del linguaggio 'alto' proprio della tradizione epico-tragica al linguaggio petrarchista, derivato anche dai contes e dai romans courtois, infine al linguaggio 'comico', derivato dalla novella realistica di tradizione boccacciana, che "spesso si fa anticortese in una contrapposizione voluta a quella della vicenda courtoise, che rappresenta lo sfondo dell'intero svolgimento drammatico». Individua anche una cifra espressiva, quella del senechismo, del tutto assente dal poema ariostesco. Particolare interesse, poi, ha l'esame di quelle parti della pièce che sono addizioni rispetto all' Orlando furioso e introducono uno slittamento di senso rispetto alla fonte, slittamento che rappresenta l'elemento maggiore caratterizzante il fenomeno della 'riscrittura'. Si tratta di uno slittamento connesso al sovrapporsi di generi letterari diversi, come quello dell'histoire tragique, oppure a condizionamenti ideologici strettamente legati alla sensibilità controriformista. Quelli, per esempio, concernenti la morale familiare e i rapporti interparentali all'interno della famiglia: soprattutto importante è la riflessione sulla natura giuridico-morale del matrimonio, che rispecchia una precisa discussione d'ordine sociale posteriore alla pubblicazione dei decreti tridentini. In un ulteriore articolo, comparso l'anno seguente in una miscellanea di studi consacrata alle Trasposizioni e riscritture nella letteratura francese, Mastroianni evidenzia, in alcuni passi della Bradamante di Garnier, i puntuali riferimenti a un grosso dibattito suscitato in Francia dalla pubblicazione di un decreto del Concilio di Trento, il Tametsi, sulla disciplina matrimoniale (1563), di cui vengono affrontati, nella pièce, due punti importanti (il consenso dei genitori e il pasticcio dei matrimoni clandestini). Numerosi comunque sono gli interventi di Garnier che denunciano un background storico e spirituale diverso da quello del testo ariostesco. Mastroianni ritrova nella pièce soprattutto la ripresa di elementi della chanson de croisade alla luce della connessione fra idea di crociata e guerra di religione, quale si riaccende in Francia all'epoca delle guerre civili; inoltre individua, nella Bradamante, un'eco precisa della politica dei Valois ai tempi del regno polacco del futuro Henri III. 